\title{
Landmarks for the Location of the Subthalamic Nucleus Using Magnetic Resonance Imaging
}

\section{Marcos para a localização do núcleo subtalâmico por ressonância magnética}

\author{
Luiza Louza Normanha ${ }^{1}$ Jéssica Rodrigues Borges Leão ${ }^{1} \quad$ Ledismar José Silva ${ }^{2}$

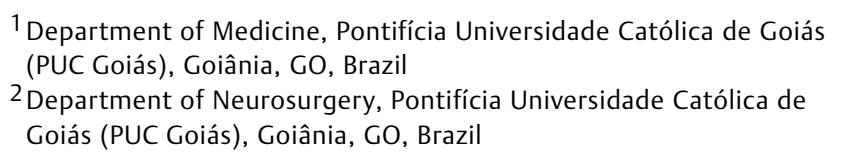 \\ Address for correspondence Ledismar José da Silva, MSc, Avenida \\ Universitária, 1.440, Setor Universitário, Goiânia, GO 74605-010, \\ Brazil (e-mail: ledismarsilva@gmail.com).
}

Arq Bras Neurocir 2020;39(4):271-278.

\section{Abstract \\ Keywords \\ - Parkinson disease \\ - deep brain stimulation \\ - subthalamic nucleus \\ - anatomical landmarks}

\section{Resumo}

Deep brain stimulation has become an option for advanced Parkinson's disease treatment since the 1990s, but the first reports are from Benabid's team, a French neurosurgeon, in the 1980s. The subthalamic nucleus (STN), more specifically its dorsolateral portion, is the most commonly stimulated brain area. One of the major aspects for a good surgical result is the accurate location of this target. Therefore, the present article aimed to identify landmarks that facilitate and refine the location of the STN using nuclear magnetic resonance imaging (NMRI) of the skull. In order to achieve this goal, a search for articles was performed using the PubMed and Science Direct online databases, and articles regarding the use of NMRI to target STN were included. The precise location of the dorsolateral portion of the STN is fundamental to achieve the best possible effect on motor symptoms and to minimize side effects. One of the most used location methods is the NMRI, associated or not with tomography or ventriculography. The location strategies can be classified as direct and indirect. Landmarks are among the indirect strategies, and the most important ones (red nucleus, Sukeroku sign, dent internal capsule sign, supramammillary commissure, mammillothalamic tract, and interpeduncular cistern) are described in the present article. The various landmarks can be combined to locate with more accuracy the dorsolateral portion of the STN and the ideal position of the electrodes to achieve the best possible clinical result.

A estimulação cerebral profunda surgiu como opção terapêutica para a doença de Parkinson avançada na década de 1990, mas os primeiros relatos são do grupo de Benabid, neurocirurgião francês, na década de 1980. O núcleo subtalâmico (NST), mais especificamente sua porção dorsolateral, é o alvo mais comumente abordado. Um dos fatores primordiais para o bom resultado cirúrgico é a localização precisa desse alvo. Assim, este artigo teve como objetivo identificar marcos que facilitem e aprimorem a localização do NST por ressonância nuclear magnética (RNM) de crânio. Para isso, foi received

February 1, 2017

accepted

May 2, 2017
DOI https://doi.org/

10.1055/s-0037-1603579. ISSN 0103-5355.
Copyright ( $\odot 2020$ by Thieme Revinter

Publicações Ltda, Rio de Janeiro, Brazil
License terms

(요 (1) $\Theta \circledast$ 
realizada busca de artigos nas bases de dados PubMed e Science Direct, incluindo-se estudos sobre o uso da RNM de crânio para localização do NST. A localização precisa da porção dorsolateral do NST é de fundamental importância para se atingir a melhor resposta clínica sobre os sintomas motores da doença e minimizar os efeitos colaterais.

Palavras-chave

- doença de Parkinson

- estimulação cerebral profunda

- núcleo subtalâmico

- marcos anatômicos A RNM de crânio é uma das modalidades de localização mais utilizadas, podendo ser associada ou não à tomografia de crânio ou à ventriculografia. As estratégias de localização podem ser classificadas em direta e indireta. Os marcos estão entre as estratégias indiretas de visualização, e os principais (núcleo rubro, sinal de Sukeroku, sinal do entalhe da cápsula interna, comissura supramamilar, trato mamilo talâmico e cisterna interpeduncular) são descritos neste artigo. Os diversos marcos podem ser utilizados de forma integrada para se obter localização mais precisa da porção dorsolateral do NST e o posicionamento ideal dos eletrodos para atingir melhor resposta clínica.

\section{Introduction}

Parkinson disease, which was described by James Parkinson in 1817 , is a degenerative and progressive disorder of the central nervous system characterized by the idiopathic loss of dopaminergic neurons, predominantly of the nigrostriatal pathway. The cardinal signs of this disease are bradykinesia, muscle stiffness, resting tremor and postural instability. ${ }^{1}$

Over the last five decades, levodopa has been considered the gold standard for the treatment of the disease. However, in the long term, motor complications can occur, such as dyskinesia and motor fluctuations, which make the clinical management of the patients difficult. ${ }^{1}$

Deep cerebral stimulation emerged as a therapeutic option for advanced Parkinson disease in the 1990s. The first reports are from the group assembled by Benabid, a French neurosurgeon, in the $1980 \mathrm{~s}^{2}$ The primary targets are the intermediate ventral nucleus of the thalamus, the subthalamic nucleus (STN), and the internal pale globe. Some of the inclusion criteria for the procedure are: refractoriness to medication, with motor fluctuations and dyskinesia induced by levodopa; refractory and incapacitating tremor; drug intolerance; absence of severe comorbidities; and absence of dementia or uncontrolled psychiatric disorders. ${ }^{3}$ The STN is the nucleus most commonly used by surgeons in the surgical treatment of Parkinson disease, targeting its dorsolateral portion. ${ }^{4}$

One of the most important factors for the surgical outcome is the accurate location of the target, because the position of the electrode determines the area through which the electric current will spread. ${ }^{5}$ Nuclear magnetic resonance imaging (NMRI) of the skull is the imaging exam currently used to find targets in stereotactic surgeries, both by the direct and indirect methods. Thus, the present article aimed to define landmarks to facilitate and refine the location of the STN by skull NMRI.

\section{Methodology}

In order to review of different location methods, we performed an article search on the PubMed and Science Direct databases, with the following descriptors: targeting; nuclear magnetic resonance imaging; NMRI; visualization; subthalamic nucleus; STN; and landmarks. After the search, the references were explored to find other relevant studies. The inclusion criteria were relevant publications with qualitative or quantitative data using cranial NMRI for STN localization. The exclusion criterion was articles in any language other than English. In the final search, duplicate references were excluded.

\section{Results and Discussion}

The STN is a small structure, with approximate dimensions of $3 \mathrm{~mm} \times 5 \mathrm{~mm} \times 12 \mathrm{~mm}$, of ovoid format, with oblique orientation, variable position, and often difficult anatomical location. ${ }^{6,7}$ Its anterior and lateral limits are wrapped by the fibers of the internal capsule. Rostromedially, it is in contact with the nuclei of the Forel fields and the posterolateral hypothalamic area, while posteromedially it is adjacent to the red nucleus (RN). Its ventral boundary is given by the cerebral peduncle and the black substance. Dorsally, the STN is limited by a portion of the lenticular issue and the uncertain zone. ${ }^{8}$ Moreover, the STN can be divided into three portions, determined by their connectivity: the dorsolateral portion, which integrates the sensory-motor circuit; the ventromedial portion, which integrates the association circuit; and the medial portion, which integrates the limbic circuit. $^{7}$

Despite being difficult to find, the precise location of the dorsolateral portion of the STN is of fundamental importance in order to achieve the best clinical response on the motor symptoms of Parkinson disease and to minimize its side effects on cognition and behavior, which are reported by $\sim$ $40 \%$ to $50 \%$ of the patients. These side effects are probably the result of a suboptimal position of the electrode and stimulation of non-motor portions of the STN. ${ }^{4}$

There are several location methods used in the context of STN stimulation, with no consensus on which would be the best. The choice of which method to be used depends on the facilities of the institution in which the procedure will be performed and 
the familiarity of the surgeon with the technique to be employed. ${ }^{9}$

Cranial NMRI is one of the most used modalities for the location of the STN, which may be associated or not with skull tomography or ventriculography. Some of the advantages of the cranial NMRI are that it enables a better demarcation of the basal nuclei, a better visualization of critical structures for the prevention of injuries that may be inadvertently caused, and a clear demarcation of the electrode's trajectory. The disadvantage of the magnetic field is nonlinear distortion, especially in the anteroposterior and medial-lateral axes. ${ }^{4,9}$

The strategies to locate the dorsolateral portion of the STN can be classified as direct and indirect. The first is the direct visualization of the nucleus in the cranial NMRI images, whereas the second one uses fixed distances or the midpoint of the line between the anterior commissure (AC) and the posterior commissure (PC). ${ }^{10}$ The main landmarks in use are cited and described in the following sections.

\section{Red Nucleus}

The RN is a landmark widely used in practice for several reasons, such as anatomical proximity to the STN, easy visualization, and visualization on $\mathrm{T} 1$ images with little distortion. ${ }^{11}$ Thus, many studies on its use determine the location of the STN.

The STN coordinates can be defined as follows: the $\mathrm{x}$ coordinate is $3 \mathrm{~mm}$ laterally to the intersection point of the most lateral edge of the RN, with the anterior edge of the RN in the axial plane, using a fast spin-echo, T2-weighted (T2-W) sequence. The $\mathrm{z}$ coordinate is $2 \mathrm{~mm}$ inferior from the upper edge of the $\mathrm{RN}$ in the coronal plane. These coordinates were based on the spatial relationship between the upper portion of the STN and the RN in the Schaltenbrand-Wahren Atlas (-Fig. 1). ${ }^{12}$

-Fig. 2 shows a coronal cut perpendicular to the AC-PC line and, through a multiplanar image, reformatted from the T2-W sequence, three hypointense signs in the upper portion of the mesencephalon, corresponding to the STN, the anterior edge of the RN and the black substance. The STN coordinates can also be determined as follows: the $\mathrm{x}$ coordinate is half of the distance between the centers of the subthalami, and the $z$ coordinate is the distance between the projection of the PC and the line that unites the centers of the subthalami in the coronal plane. The y coordinate is the distance between the anterior edge of the RN and the projection of the PC, verified by the sagittal view. ${ }^{13}$

\section{Sukeroku Sign and Dent Internal Capsule Sign}

Using the short tau inversion recovery (STIR) sequence in the coronal plane, in an incidence perpendicular to the AC-PC line and at the internal auditory canal level, the STN and the black substance are found in the same plane, with the first one located cranially to the second. Taking this relationship as a base, the black substance can be described as an eye, with the STN assuming the shape of the makeup of Sukeroku, a character in a Japanese Kabuki play. In the axial plane, parallel to the AC-PC line and at the level of the mammillary body, the STN can be seen more medially as a notch in the contour of the internal capsule (-Fig. 3). ${ }^{14}$

\section{Supramammillary Commissure}

The supramammillary commissure (SMC) is one of the structures that binds the right and left cerebral hemispheres, making anatomical relations previously with the optical tracts, the mammillary bodies and the middle-commissural line, medially and subsequently with the RN. In the coronal section (-Fig. 4), the commissural midpoint (CMP) is 5 to $7 \mathrm{~mm}$ below the midpoint of the AC-PC line. The top edge of the SMC is $4 \mathrm{~mm}$ below the midpoint of the AC-PC line, and at the same level as the intended target in the STN, but medial to it at $12 \mathrm{~mm}$. In the axial section (-Fig. 5), the images show that the central portion of the SMC is between $3 \mathrm{~mm}$ and $4 \mathrm{~mm}$ posteriorly to the midpoint of the AC-PC line, while the target is $12 \mathrm{~mm}$ laterally to the CMP. In the sagittal section (-Fig. 6), the upper edge of the SMC and the target are at the

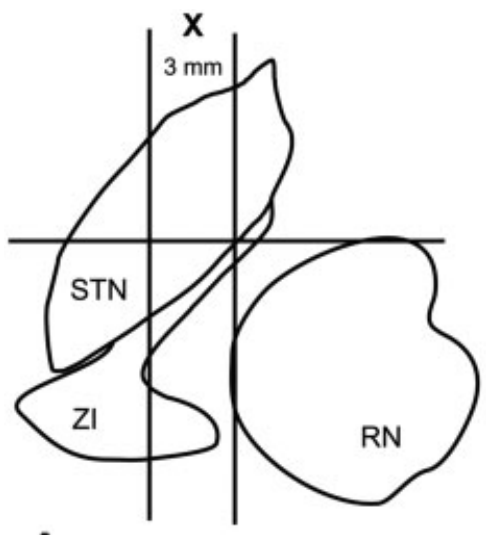

A

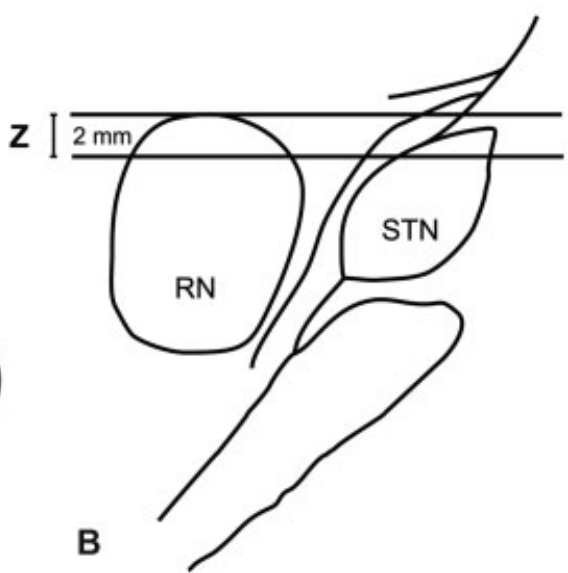

Fig. 1 STN location using the RN ( $x=3 \mathrm{~mm}$ laterally to the most lateral edge; $z=2 \mathrm{~mm}$ inferiorly to the upper edge of the RN). (A) Axial projection. (B) Coronal projection. ${ }^{12}$ Abbreviations: RN, red nucleus; STN, subthalamic nucleus; ZI, zona incerta. 

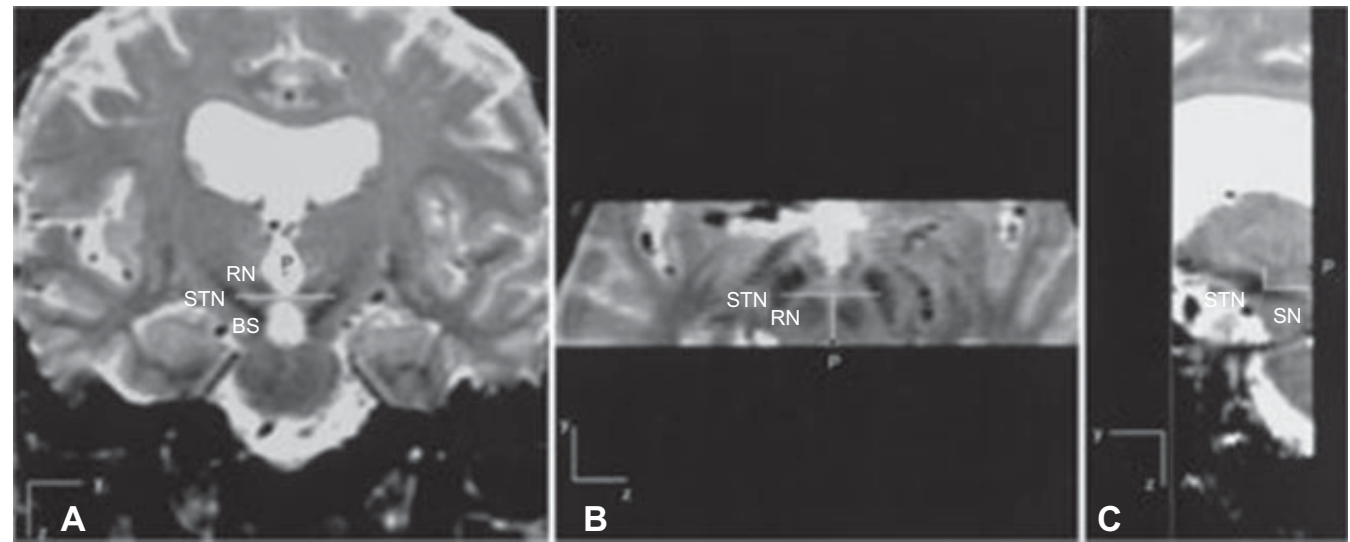

Fig. 2 STN visualization using a multiplanar, coronal, reformatted T2-weighted image. (A) Coronal image showing an incidence perpendicular to the plane of the line between the anterior commissure and the posterior commissure, with three hypointense structures corresponding to the STN, the anterior edge of the RN and the BS. The $x$ coordinate is calculated as half of the distance between the centers of the two STNs. The $z$ coordinate represents the distance between $\mathrm{P}$ (projection of the posterior commissure) and the line that crosses the STN. The horizontal line represents the level of the cutting plane of the axial view of B. (B) Axial image showing the RN and the STN. The y coordinate represents the distance (vertical white line) between $\mathrm{P}$ and the horizontal white line. This line runs through the anterior edge of the RN and the center of the two STNs. (C) Parasagittal view. The horizontal and vertical white lines are projections of the white lines of the axial and coronal views, and they represent the $y$ and $z$ coordinates respectively. ${ }^{13}$ Abbreviations: RN, red nucleus; STN, subthalamic nucleus; SN, substantia nigra.
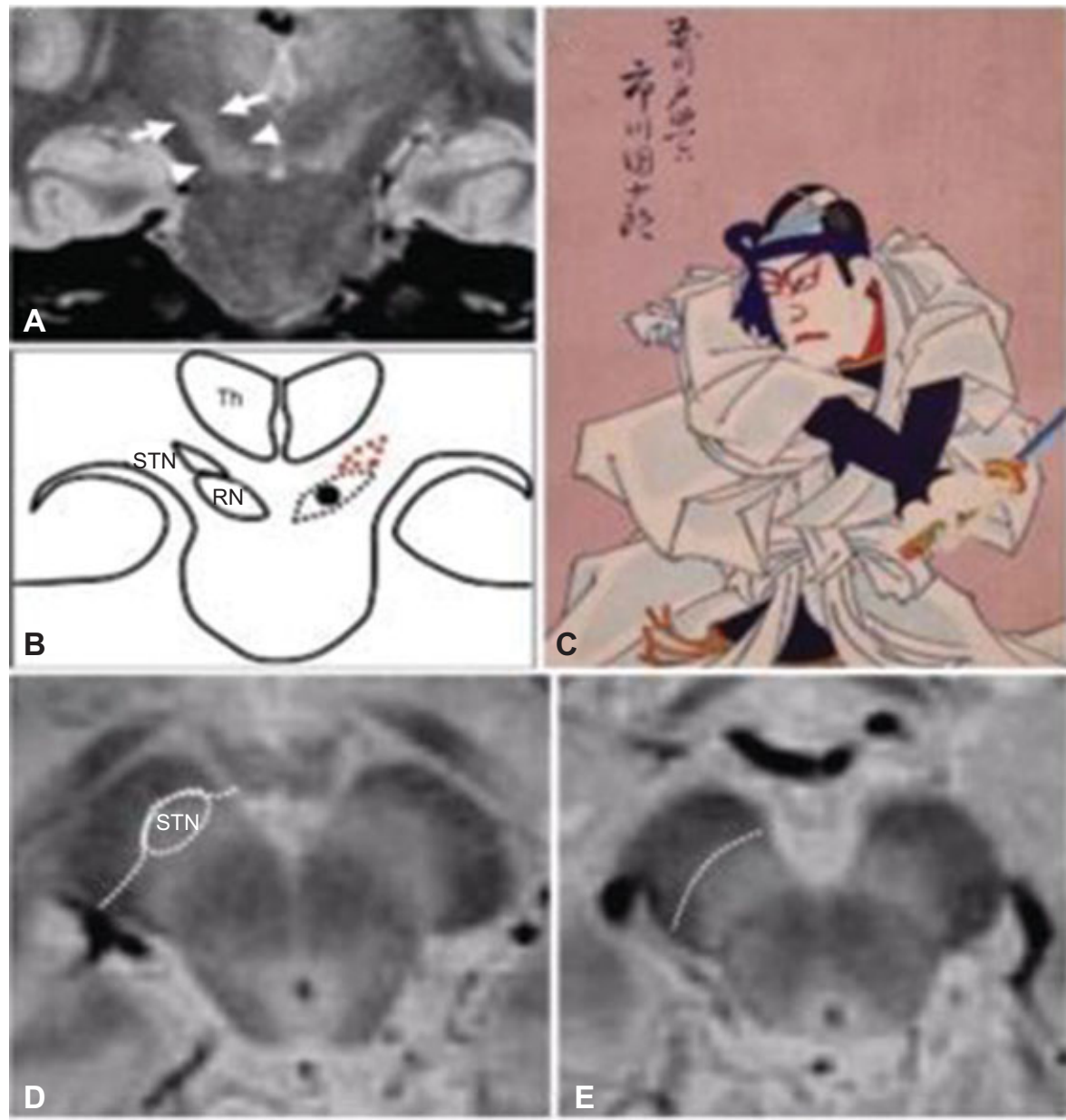

Fig. 3 Sukeroku sign and dent internal capsule sign. (A) The arrows point to the STN, and the arrow heads point to the black substance. (B) Schematic drawing of the Sukeroku sign. (C) Sukeroku, a character in a Japanese Kabuki play, with his distinctive made-up eyes. (D and E) Dent internal capsule sign. ${ }^{14}$ Abbreviations: RN, red nucleus; STN, subthalamic nucleus; Th, thalamus. 

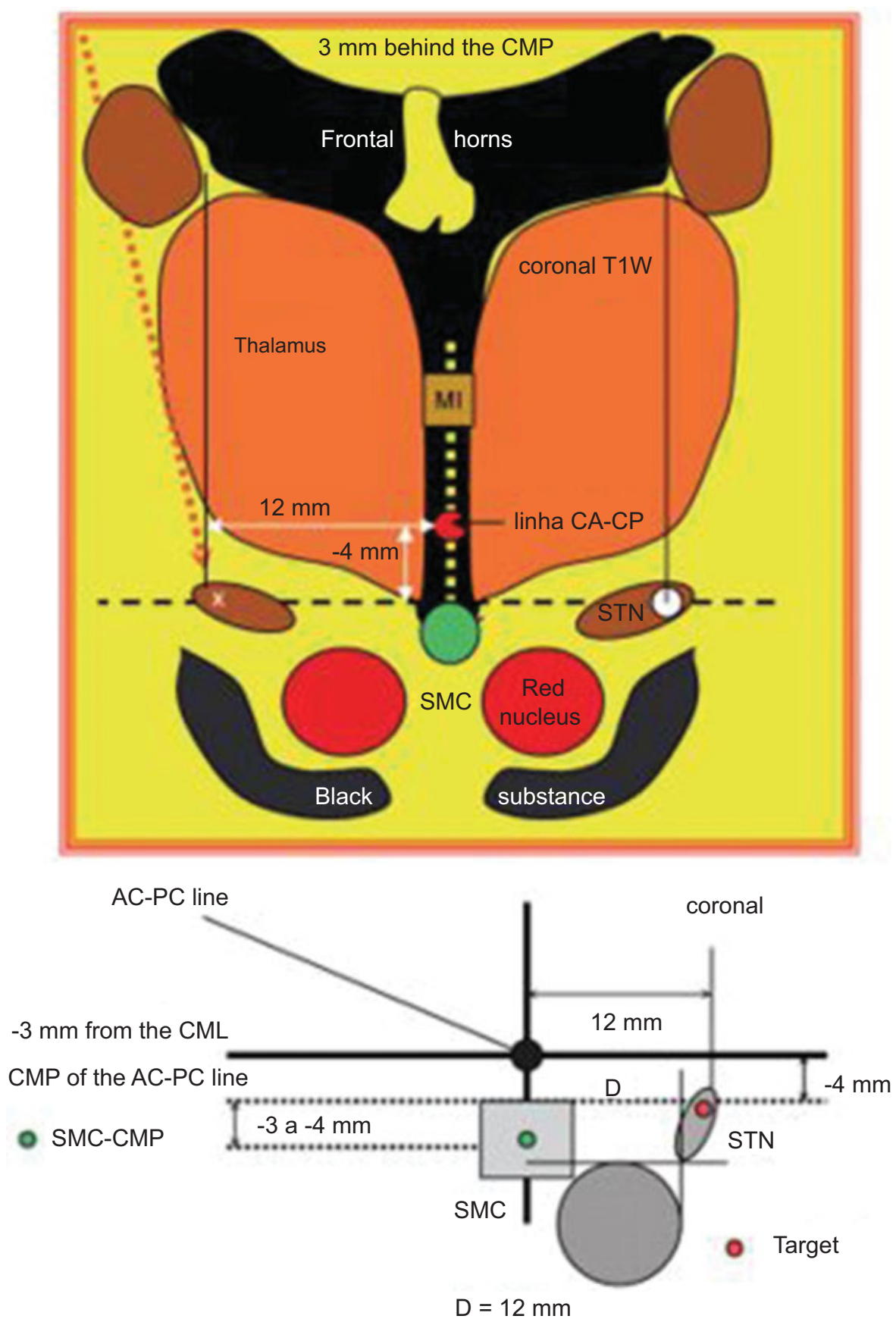

Coronal view of the thinnest portion of the SMC, $3 \mathrm{~mm}$ behind the CMP of the AC-PC line

Fig. 4 Coronal view showing the anatomy of the STN and targets. ${ }^{15}$ Abbreviations: AC, anterior commissure; SMC, supramammillary commissure; PC, posterior commissure; CML, commissural midline; STN, subthalamic nucleus; CMP commissural midpoint.

same level, $3 \mathrm{~mm}$ posteriorly and $4 \mathrm{~mm}$ below the midpoint of the AC-PC line. ${ }^{15}$

In order to observe the so-called mustache sign, it is necessary to locate the thicker portion of SMC in the coronal sections and, from its middle portion, a line with a $30^{\circ}$ angle from the horizon is drawn to the lateral part of the skull. So, the length of the short side of this triangle opposite to the $30^{\circ}$ angle is $4 \mathrm{~mm}$, whereas the long side is $12 \mathrm{~mm}$, and the hypotenuse, $12.3 \mathrm{~mm}$. A line traced at the lower perpendicular part from the caudate thalamus groove will intersect the $30^{\circ}$ angle of the mustache on the STN target. This method has disadvantages when it is used in the brains of elderly patients due to the increase and distortion of the ventricle.

Both landmarks were visualized in the present study through NMRI in a cranial magnetization-prepared rapid gradient-echo (MP-RAGE) sequence with T2-W images. ${ }^{15}$

\section{Mammillothalamic Tract}

The mammillothalamic tract is easily visualized in NMRI images of the skull, since it is a small, hypodense and round image of the third ventricle. It is possible to find it in axial 


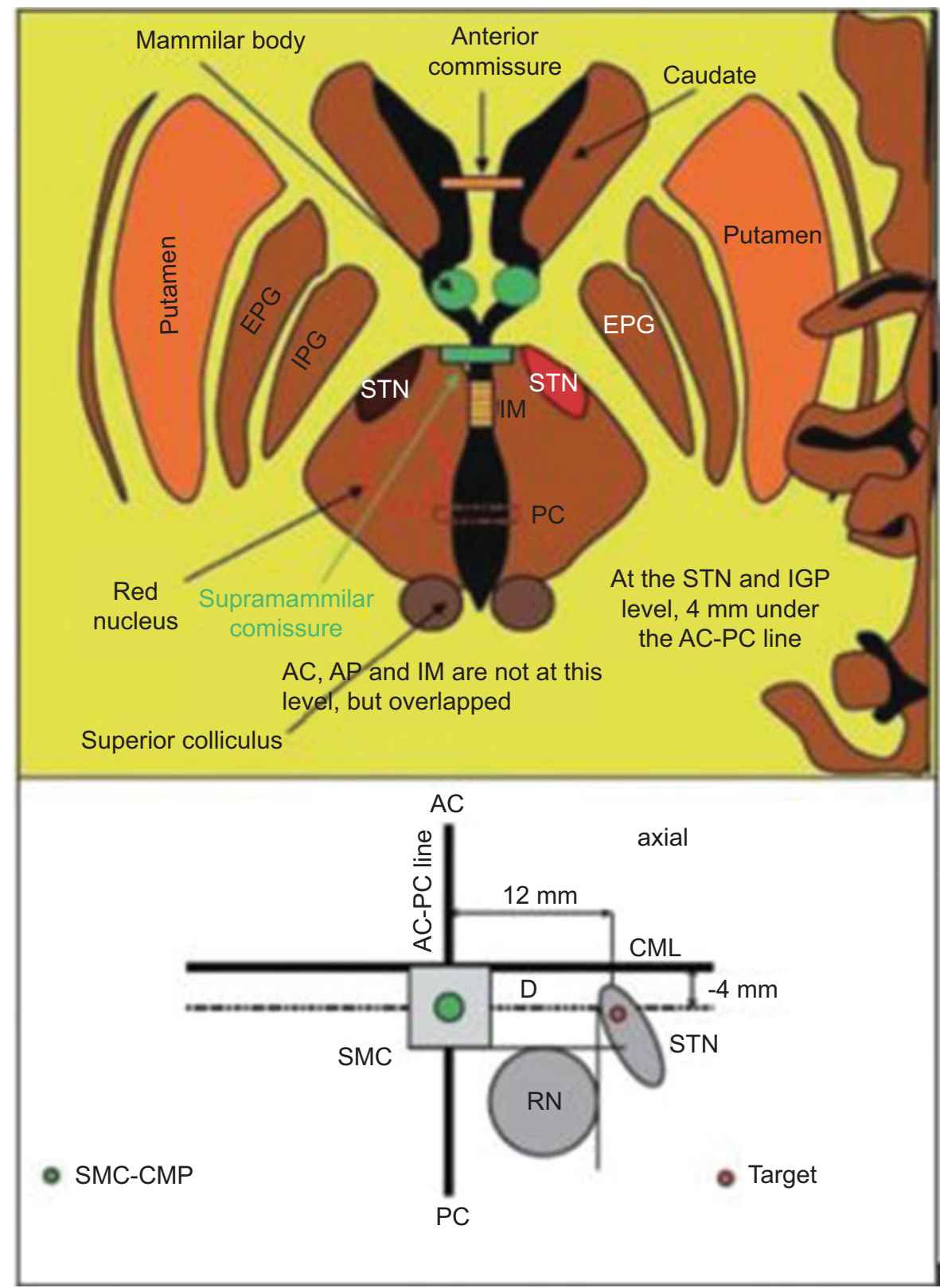

Fig. 5 Axial view showing the anatomy of the STN and targets. ${ }^{15}$ Abbreviations: AC anterior commissure; SMC, supramammillary commissure; PC, posterior commissure; EPG, external pale globe; IPG, intermediate pale globe; CML commissural midline; IM, intermediate mass; RN, red nucleus; STN, subthalamic nucleus; CMP, commissural midpoint.

sections, $\sim 5$ to $6 \mathrm{~mm}$ medially to the anterior edge of the STN. The center of the mammillothalamic tract may be a good anterior landmark of the STN, because it is located $~$ $4 \mathrm{~mm}$ anteriorly to the RN (- Fig. 7 ).

\section{Interpeduncular Cistern}

The interpeduncular cistern (IC) is a strong predictor of the STN laterality, and can be used as an additional landmark for several reasons, such as its anatomical proximity to the STN, its easy visualization, the fact that it can be observed on T1weighted images with few distortions, and the fact that it provides a constant point that assists in the standardization of the patients. It is possible to locate the IC in the coronal plane as the midpoint of the vertical distance made by the shape of the sagittal view of the bridge and the peduncle in the midline, which form a cursive "a." The target can be found using the mathematical formula: $x$ coordinate for the $\mathrm{STN}=0.6 \mathrm{x}$ IC width $+7 \mathrm{~mm}\left(-\right.$ Fig. 8). ${ }^{11}$

\section{Conclusion}

There are several landmarks to visualize the STN, and there is no consensus on the best one to be used in each situation. However, it is known that they can be used in an integrated way to obtain a more accurate location of the dorsolateral portion of the STN and, consequently, the ideal position of the electrodes to achieve a better clinical response. 


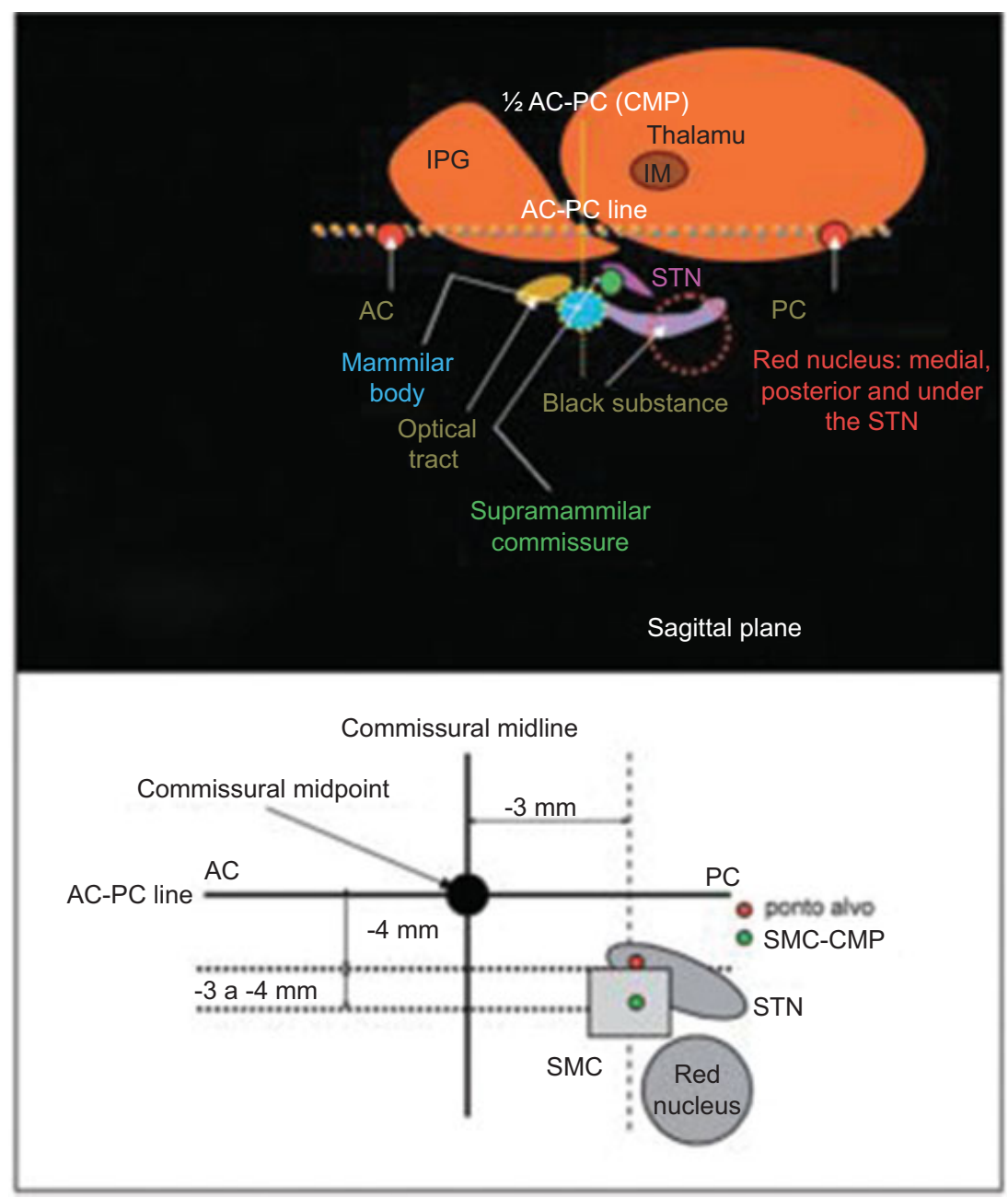

Fig. 6 Sagittal view showing the anatomy of the STN and targets. ${ }^{15}$ Abbreviations: AC anterior commissure; SMC, supramammillary commissure; PC, posterior commissure; IPG, intermediate pale globe; IM, intermediate mass; STN, subthalamic nucleus; CMP, commissural midpoint.

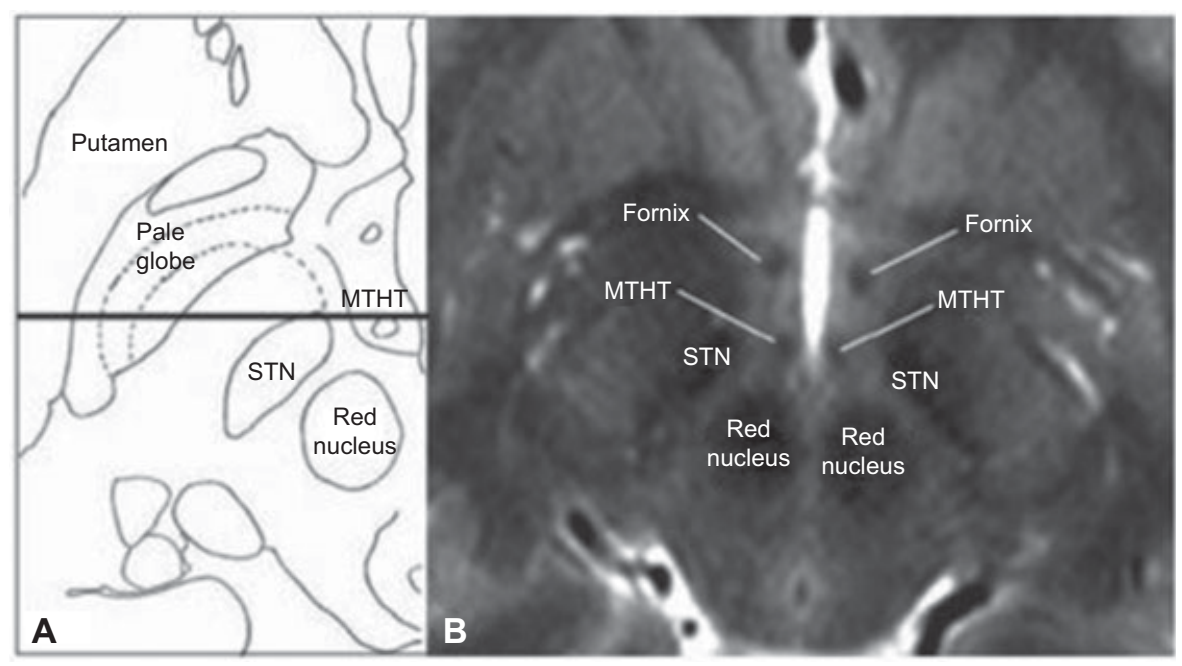

Fig. 7 Anatomical relationship between the mammillothalamic tract and the STN. (A) Illustration of the anatomy of the subthalamic region 4-5 mm below the plane between the AC and PC, adapted from the Schaltenbrand-Wahren Atlas. The dark line passes through the anterior pole of the STN and the mammillothalamic tract. (B) Axial image of cranial NMRI in T2, $4 \mathrm{~mm}$ below the plane of the AC-PC. The STN, the red nucleus, the mammillothalamic tract and the fornix are visualized in this section. ${ }^{16}$ Abbreviations: AC, anterior commissure; PC, posterior commissure; STN, subthalamic nucleus; NMRI, nuclear magnetic resonance imaging; MTHT, mammillothalamic tract. 


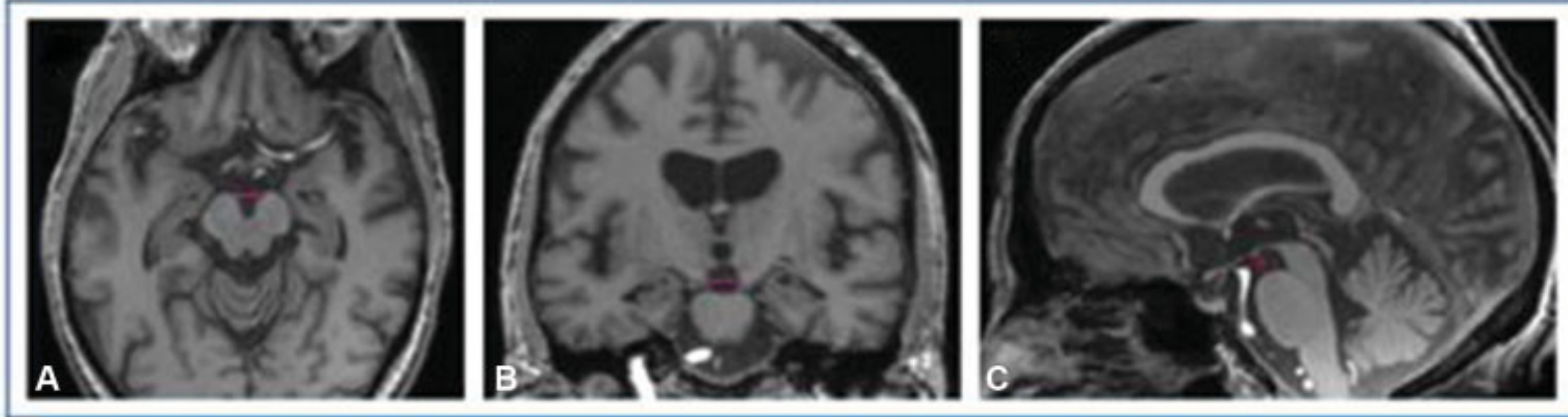

Fig. 8 Visualization of the interpeduncular cistern in the (A) axial, (B) coronal and (C) sagittal views. ${ }^{11}$

\section{Conflict of Interests}

The authors have no conflict of interests to declare.

\section{References}

1 Smith Y, Wichmann T, Factor SA, DeLong MR. Parkinson's disease therapeutics: new developments and challenges since the introduction of levodopa. Neuropsychopharmacology 2012;37(01): 213-246

2 Groiss SJ, Wojtecki L, Südmeyer M, Schnitzler A. Deep brain stimulation in Parkinson's disease. Ther Adv Neurol Disorder 2009;2(06):20-28

3 Kern DS, Kumar R. Deep brain stimulation. Neurologist 2007;13 (05):237-252

4 Brunenberg EJL, Platel B, Hofman PAM, Ter Haar Romeny BM, Visser-Vandewalle V. Magnetic resonance imaging techniques for visualization of the subthalamic nucleus. J Neurosurg 2011;115 (05):971-984

5 Bronte-Stewart HB. Surgical placement of deep brain stimulation leads for the treatment of movement disorders: intraoperative aspects. In: Marks WJ Jr, editor. Deep brain stimulation management. Cambridge: Cambridge University Press, Deep brain stimulation management; 2011:20-31

6 Toda H, Sawamoto N, Hanakawa T, et al. A novel composite targeting method using high-field magnetic resonance imaging for subthalamic nucleus deep brain stimulation. JNeurosurg 2009;111(04):737-745

7 Massey LA, Yousry TA. Anatomy of the substantia nigra and subthalamic nucleus on MR imaging. Neuroimaging Clin $\mathrm{N}$ Am 2010;20(01):7-27
8 Hamani C, Saint-Cyr JA, Fraser J, Kaplitt M, Lozano AM. The subthalamic nucleus in the context of movement disorders. Brain 2004;127(Pt 1):4-20

9 Chen SY, Tsai ST, Lin SH. Controversial issues in deep brain stimulation in Parkinson's disease. In: Finkelstein D, editor. Towards new therapies for Parkinson's Disease. RijekaIn Tech Europe2011:1-20. Available at: http://cdn.intechopen.com/pdfs-wm/22876.pdf. Access: 2016(Set 12)

10 Starr PA. Placement of deep brain stimulators into the subthalamic nucleus or Globus pallidus internus: technical approach. Stereotact Funct Neurosurg 2002;79(3-4):118-145

11 Deogaonkar M, Freitas T, Machado A, Rezai A. Subthalamic nucleus targeting using interpeduncular cistern as an internal landmark. Neurosurgery 2011;69(2, Suppl Operative)ons225-ons229

12 Andrade-Souza YM, Schwalb JM, Hamani C, et al. Comparison of three methods of targeting the subthalamic nucleus for chronic stimulation in Parkinson's disease. Neurosurgery 2008;62(Suppl 2):875-883

13 Bejjani BP, Dormont D, Pidoux B, et al. Bilateral subthalamic stimulation for Parkinson's disease by using three-dimensional stereotactic magnetic resonance imaging and electrophysiological guidance. J Neurosurg 2000;92(04):615-625

14 Taoka T, Hirabayashi H, Nakagawa H, et al. "Sukeroku sign" and "dent internal-capsule sign"-identification guide for targeting the subthalamic nucleus for placement of deep brain stimulation electrodes. Neuroradiology 2009;51(01):11-16

15 Lee C, Young B, Sanders MF. The role of the supramammillary commissure in MR localization of the subthalamic nucleus. Stereotact Funct Neurosurg 2006;84(5-6):193-204

16 Caire F, Maubon A, Moreau JJ, Cuny E. The mamillothalamic tract is a good landmark for the anterior border of the subthalamic nucleus on axial MR images. Stereotact Funct Neurosurg 2011;89(05):286-290 